\begin{tabular}{|c|l|}
\hline Title & Efficient and selective epoxidation of styrene with TBHP catalyzed by A u25 clusters on hydroxyapatite \\
\hline Author(s) & Liu, Y ongmei; Tsunoyama, Hironori; A kita, Tomoki; T sukuda, Tatsuya \\
\hline Citation & $\begin{array}{l}\text { Chemical Communications, 46(4), 550-552 } \\
\text { https://doi.org/40.1039/6921082b }\end{array}$ \\
\hline Issue Date & $2010-01-28$ \\
\hline Doc URL & http://hdl.handle.net/2115/44765 \\
\hline Rights & Chem. Commun., 2010, 46, 550-552- Reproduced by permission of The Royal Society of Chemistry (RSC) \\
\hline Type & article (author version) \\
\hline File Information & Cc46-4_550-552.pdf \\
\hline
\end{tabular}

Instructions for use 


\title{
Efficient and selective epoxidation of styrene with TBHP catalyzed by $\mathrm{Au}_{25}$ clusters on hydroxyapatite ${ }^{\dagger}$
}

\author{
Yongmei Liu, ${ }^{a}$ Hironori Tsunoyama, ${ }^{a}$ Tomoki Akita, ${ }^{b c}$ and Tatsuya Tsukuda ${ }^{* a c}$ \\ Received (in $X X X, X X X) X$ th $X X X X X X X X X 200 X$, Accepted $X$ th $X X X X X X X X X 200 X$ \\ ${ }_{5}$ First published on the web Xth $X X X X X X X X X 200 X$ \\ DOI: $10.1039 / b 000000 x$
}

\begin{abstract}
$\mathrm{Au}_{25}$ clusters supported on hydroxyapatite oxidized styrene in toluene with $100 \%$ conversion and $92 \%$ selectivity to the epoxide, under optimum conditions and using anhydrous tert-butyl 10 hydroperoxide (TBHP) as an oxidant.
\end{abstract}

In 1998, Haruta and coworkers demonstrated for the first time that supported Au nanoparticles (AuNPs) are effective for the direct epoxidation of propene using molecular oxygen. ${ }^{1}$ Since then, supported gold catalysts have been used for the selective 15 epoxidation/oxidation of various alkenes such as styrene, cyclohexene, cis-cyclooctene and trans-stilbene. ${ }^{2-7}$ A major current challenge is to use $\mathrm{O}_{2}$ as a green oxidant. ${ }^{3,4,5 \mathrm{c}}$ Lambert and coworkers have demonstrated that $\mathrm{Au}_{55}$ clusters supported on silica can catalytically activate $\mathrm{O}_{2}$ for styrene epoxidation 20 because of the electronic structures of the clusters, althought the yield of the epoxide is not high $(\sim 5 \%) .{ }^{4}$ This work hints at the possibility that there is a optimal cluster size for the efficient and selective oxidation of alkenes. Here we focus on the epoxidation of styrene and aim to systematically study the ${ }_{25}$ effect on the catalytic activity of the size of Au clusters that are immobilized on hydroxyapatite $\left(\mathrm{HAP} ; \mathrm{Ca}_{10}\left(\mathrm{PO}_{4}\right)_{6}(\mathrm{OH})_{2}\right){ }^{8}$ We use tert-butyl hydroperoxide (TBHP) as an oxidant since it is known to be more effective than $\mathrm{O}_{2}$ for alkene oxidations. $^{5-7}$ We describe the synthesis of HAP-supported ${ }_{30} \mathrm{Au}_{25}$ clusters; they show a higher catalytic performance (100\% conversion and $92 \%$ selectivity to the epoxide) than larger analogs.

The preparation of HAP-supported $\mathrm{Au}_{25}$ catalysts is depicted in Scheme 1. The basic idea is to use as a precursor 35 ligand-protected Au clusters with a well-defined core size. ${ }^{4,9}$ In brief, we first deposit $\mathrm{Au}_{25}$ clusters protected by 18 glutathionate (GS) ligands, $\mathrm{Au}_{25}(\mathrm{SG})_{18}$, on an HAP support and then calicine the composite to remove the GS ligands. The $\mathrm{Au}_{25}(\mathrm{SG})_{18}$ cluster is a water-soluble, stable cluster 40 compound that we first identified in 2005. ${ }^{10}$ Recent single crystal XRD results on $\mathrm{Au}_{25}\left(\mathrm{SC}_{2} \mathrm{H}_{4} \mathrm{Ph}\right)_{18}$ revealed that it is composed of an icosahedral $\mathrm{Au}_{13}$ core fully protected by six

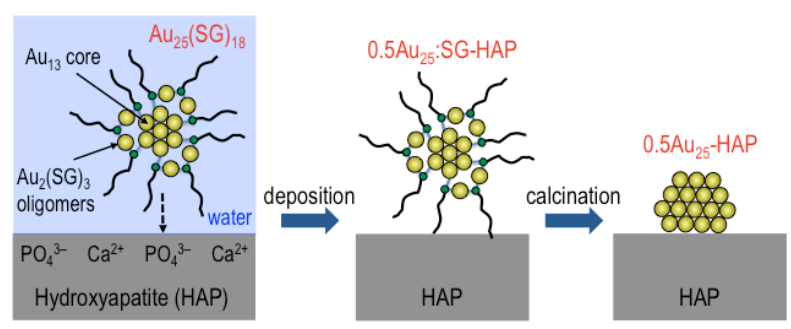

Scheme 1. Synthetic procedure of HAP-supported $\mathrm{Au}_{25}$ clusters.
${ }_{55} \mathrm{Au}_{2}\left(\mathrm{SC}_{2} \mathrm{H}_{4} \mathrm{Ph}\right)_{3}$ oligomers. ${ }^{11}$ In the present study, HAP was used as a support material for the Au clusters. ${ }^{12}$ We expected that $\mathrm{Au}_{25}(\mathrm{SG})_{18}$ could be adsorbed on HAP by electrostatic interaction between $\mathrm{Ca}^{2+} / \mathrm{PO}_{4}{ }^{3-}$ moieties and the GS ligands, and that HAP could stabilize bare $\mathrm{Au}_{25}$ clusters against 60 sintering due to strong interaction with $\mathrm{PO}_{4}{ }^{3-}$ moiety. ${ }^{13}$

The $\mathrm{Au}_{25}(\mathrm{SG})_{18}$ clusters prepared by the reported procedure $^{10}$ and HAP were dispersed in water. The purity of the $\mathrm{Au}_{25}(\mathrm{SG})_{18}$ sample was confirmed by the profile and extinction coefficient of the optical spectrum and 65 thermogravimetric (TG) analysis. After the mixture was stirred for $4 \mathrm{~h}$, the composite of $\mathrm{Au}_{25}(\mathrm{SG})_{18}$ and HAP was collected by filtration. The $\mathrm{Au}_{25}(\mathrm{SG})_{18}$ clusters were found to be adsorbed completely on HAP as evidenced by the colorless filtrate (ESI, $\dagger$ Fig. S1). The Au loading of the composites 70 thus obtained is $0.5 \mathrm{wt} \%$ (ESI, $\dagger$ Table S1), so the composite is hereafter referred to as $0.5 \mathrm{Au}_{25}$ :SG-HAP. Similar profiles of the optical spectra for $\mathrm{Au}_{25}(\mathrm{SG})_{18}$ and the $0.5 \mathrm{Au}_{25}$ :SG-HAP composite (ESI, $\dagger$ Fig. S2) indicate that $\mathrm{Au}_{25}(\mathrm{SG})_{18}$ is adsorbed intact on the HAP surface (Scheme 1). High-angle 75 annular dark-field scanning transmission electron microscopy (HAADF-STEM) confirmed that monodisperse Au clusters with an average diameter of $1.0 \pm 0.4 \mathrm{~nm}$ are distributed in the $0.5 \mathrm{Au}_{25}$ :SG-HAP composite (ESI, $\uparrow$ Fig. S3). The diameter of the Au core is comparable to that of $\mathrm{Au}_{25}(\sim 0.9 \mathrm{~nm})$, assuming 80 a spherical shape.

The $0.5 \mathrm{Au}_{25}$ :SG-HAP composite was then incubated for removal of the thiolate ligands. The results of thermogravimetric analysis revealed a $49 \%$ weight loss of $\mathrm{Au}_{25}(\mathrm{SG})_{18}$ after calcination at $300{ }^{\circ} \mathrm{C}$ in vacuo for $2 \mathrm{~h}$ (ESI, $\dagger$ ${ }_{85}$ Fig. S4); this weight corresponded to the calculated weight of the GS ligands in $\mathrm{Au}_{25}(\mathrm{SG})_{18}$ (53\%). Thus, $0.5 \mathrm{Au}_{25}$ :SG-HAP was calcined under the above mentioned conditions to remove the GS ligands. This removal was confirmed by inductively coupled plasma (ICP) measurements. After calcination, the 90 sulfur content reduced from $0.058 \mathrm{wt} \%$ to $0.005 \mathrm{wt} \%$, which was comparable to the amount of sulfur impurity in HAP. An HAADF-STEM image of the resulting $\mathrm{Au}_{25}$-HAP shows that most of the clusters are 1.2-1.5 $\mathrm{nm}$ in size (Fig. 1A). Fig. 1B represents a histogram of the Au cluster size determined by 95 measuring more than 400 particles. The average diameter is determined to be $1.4 \pm 0.6 \mathrm{~nm}$, larger than that for $0.5 \mathrm{Au}_{25}$ :SG-HAP (ESI, $\uparrow$ Fig. S3). Close inspection of Fig. $1 \mathrm{~A}$ reveals Au clusters with non-spherical morphology. Possible explanations for these observations are that (1) larger clusters 100 form because of sintering, or (2) $\mathrm{Au}_{25}$ clusters with various morphologies are formed in the heat-induced structural 
arrangement and because of the strong interaction between $\mathrm{Au}_{25}$ and HAP. We believe that (2) is the correct explanation since the cluster diameter does not change appreciably even when the loading of $\mathrm{Au}_{25}(\mathrm{SG})_{18}$ is reduced to $0.2 \mathrm{wt} \%$.
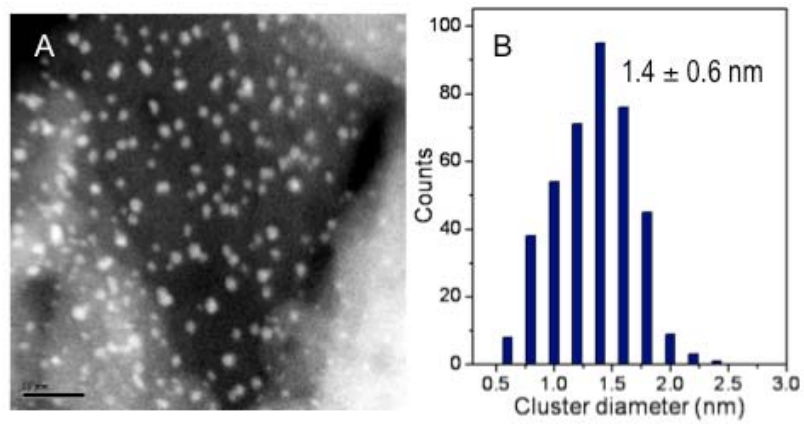

Fig. 1 (A) Representative HAADF-STEM image of $0.5 \mathrm{Au}_{25}-\mathrm{HAP}$ and (B) size distribution of the $\mathrm{Au}$ clusters. The bar in panel (A) represents $10 \mathrm{~nm}$.

For comparison, other 0.5Au-HAP samples were prepared using $\mathrm{HAuCl}_{4}$ as the precursor by the conventional method such as impregnation (IP), deposition precipitation (DP), and adsorption (Ad) (ESI $\dagger$ ). These samples are denoted as 0.5AuHAP(IP), 0.5Au-HAP(DP) and 0.5Au-HAP(Ad), respectively. 10 Gold contents were confirmed by ICP measurement (ESI, $\uparrow$ Table S1). Their Au particle sizes were measured by conventional TEM. The average diameters for $0.5 \mathrm{Au}-$ HAP(Ad) and 0.5Au-HAP(IP) were determined to be $1.7 \pm 1.2$ and $6.0 \pm 3.7 \mathrm{~nm}$, respectively, whereas the Au clusters for $150.5 \mathrm{Au}-\mathrm{HAP}(\mathrm{DP})$ were polydisperse with sizes in the range of 1-20 nm (ESI, † Fig. S5).

The Au-HAP catalysts were also characterized by UV-vis diffuse reflectance spectroscopy. Fig. 2 compares the optical spectra of the four Au-HAP catalysts. The sharp peaks 20 associated with quantized electronic structures of $A_{25}(G S)_{18}$ on HAP (ESI, $\dagger$ Fig. S1) are smeared out after calcination (curve a). This change is consistent with the generation of structural isomers of $\mathrm{Au}_{25}$ during calcination and/or by interaction between $\mathrm{Au}_{25}$ and the HAP support. The surface

${ }_{25}$ plasmon (SP) band is absent in $0.5 \mathrm{Au}_{25}-\mathrm{HAP}$ (curve a), whereas it is apparent for 0.5Au-HAP(Ad), 0.5Au-HAP(IP), and 0.5Au-HAP(DP) (curves b-d). This observation indicates that the Au clusters in $0.5 \mathrm{Au}_{25}-\mathrm{HAP}$ are smaller than those in the other samples. Given that optical spectroscopy probes the

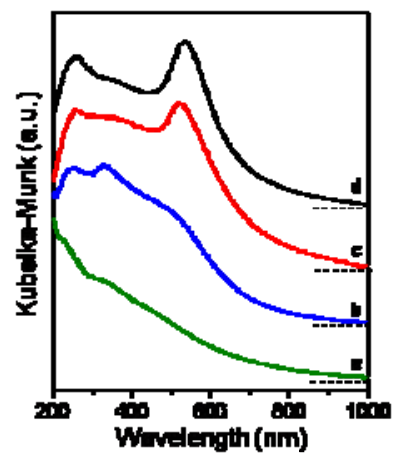

Fig. 2 Diffuse reflectance UV-vis spectra of a) $0.5 \mathrm{Au}_{25}-\mathrm{HAP}$, b) 0.5Au-HAP(Ad), c) 0.5Au-HAP(IP), and d) 0.5Au-HAP(DP). electronic structure of the ensemble of Au clusters and is highly sensitive to the presence of AuNPs ( $>2 \mathrm{~nm}$ ), curve a in Fig. 2 indicates that the population of Au clusters larger than $2 \mathrm{~nm}$ is negligibly small. These inferences are in consistent 50 with the HAADF-STEM results (Fig. 1B). The BET surface areas of the Au-HAP catalysts were $\sim 30 \mathrm{~m}^{2} / \mathrm{g}$ (ESI, $\dagger$ Table S1).

To reveal the effect on the catalytic activity of the size of $\mathrm{Au}$ clusters, the catalytic performance of monodisperse $\mathrm{Au}$ 55 catalysts $0.5 \mathrm{Au}_{25}-\mathrm{HAP}, 0.5 \mathrm{Au}-\mathrm{HAP}(\mathrm{Ad})$ and $0.5 \mathrm{Au}-\mathrm{HAP}(\mathrm{IP})$ was compared. Oxidation of styrene (1) in toluene at $80{ }^{\circ} \mathrm{C}$ using anhydrous TBHP as an oxidant yielded styrene oxide (2) as a major product in every case, whereas acetophenon (3), benzaldehyde (4), benzylalcohol (5), and benzoic acid (6) 60 were also produced. $\ddagger^{14}$ It was essential to use toluene as a solvent to obtain $\mathbf{2}$ in a high yield, in sharp contrast to the case of $\mathrm{Au} / \mathrm{graphite}{ }^{3}$ and $\mathrm{Au} / \mathrm{SiO}_{2}{ }^{4}{ }^{4}$ The use of anhydrous toluene and TBHP was also important for enhancing the yield of 2 . Compounds 3-6 were produced by the oxidation of $\mathbf{1}$ as well 65 as the toluene solvent; for example, the yields of 4-6 by $0.5 \mathrm{Au}_{25}-\mathrm{HAP}$ exceed $100 \%$ with respect to $\mathbf{1}$ (ESI, $\dagger$ Fig. S7). For simplicity, we focus here on the conversion of $\mathbf{1}$ to 2 .

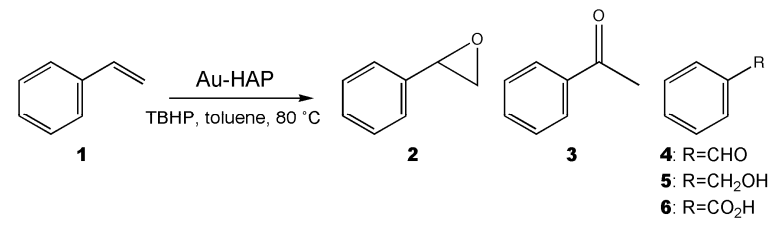

Fig. 3A shows the time evolution of the conversion of $\mathbf{1}$., 70 estimated from the GC yield of $\mathbf{1}$. The rate constants of the conversion are estimated by assuming first-order kinetics with respect to the substrate (1) (ESI, † Fig. S8, Table S2). The rate of conversion for $0.5 \mathrm{Au}_{25}-\mathrm{HAP}$ is comparable to that of $0.5 \mathrm{Au}-\mathrm{HAP}(\mathrm{Ad})$, but slightly larger than that of $0.5 \mathrm{Au}-$ 75 HAP(IP). However, the conversion reaches $>90 \%$ for all the catalysts after $>12 \mathrm{~h}$. These resuts suggest that Au clusters on HAP can effectively oxidize 1 regrdless of the size. The selectivity of the Au-HAP catalysts toward 2 was calculated using the equation $100 \times \mathrm{Y} 2 /(100-\mathrm{Y} \mathbf{1})$, where $\mathrm{Y} 1$ and $\mathrm{Y} 2$ 80 represent the GC yields (in \%) of $\mathbf{1}$ and 2, respectively. The selectivity of 2 thus estimated is plotted in Fig. 3B as a function of the reaction time. Interestingly, the selectivity of $0.5 \mathrm{Au}_{25}$-HAP (92-95\%) is much higher than those (50-60\%) of $0.5 \mathrm{Au}-\mathrm{HAP}(\mathrm{Ad})$ and $0.5 \mathrm{Au}-\mathrm{HAP}(\mathrm{IP})$. The remarkable ${ }_{85}$ difference in the selectivity between $0.5 \mathrm{Au}_{25}$ - $\mathrm{HAP}$ and $0.5 \mathrm{Au}-$
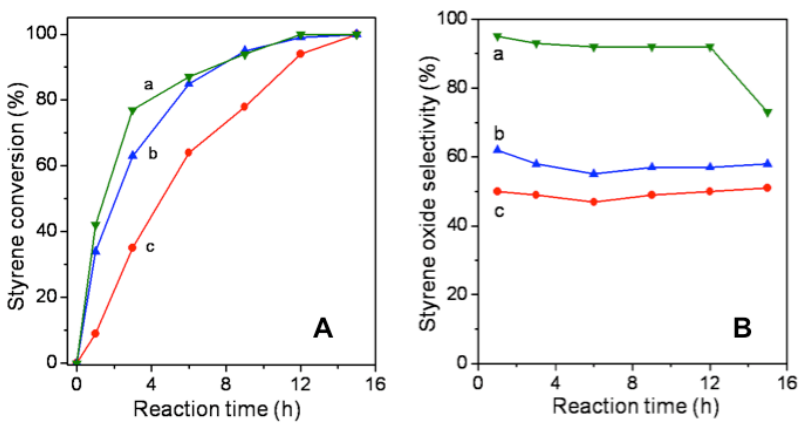

Fig. 3 Time evolution of (A) conversion of $\mathbf{1}$ and (B) selectivity of $\mathbf{2}$ for a) $0.5 \mathrm{Au}_{25}-\mathrm{HAP}$, b) $0.5 \mathrm{Au}-\mathrm{HAP}(\mathrm{Ad})$, and c) $0.5 \mathrm{Au}-\mathrm{HAP}(\mathrm{IP})$. 
HAP(Ad) may reflect the difference in geometrical (Fig. 1A) and/or electronic structures (Fig. 2) of the $\mathrm{Au}$ clusters although their average diameters appeared to be similar by TEM observation. Because of the high selectivity, the ${ }_{5} 0.5 \mathrm{Au}_{25}-\mathrm{HAP}$ catalyst gave the highest yield of 2 , reaching $92 \%$ at 12 h. $^{15}$ To our knowledge, this yield of styrene oxide is one of the highest reported so far. ${ }^{2-7}$ Very recently, AuNPs $(3 \mathrm{~nm})$ stabilized by an oligomer of ionic liquid exhibited a styrene conversion of $100 \%$ with a selectivity to styrene oxide 10 of $90 \%$, but they were gradually deactivated during the reuse process. $^{7 \mathrm{~b}}$

What is the reason for the high selectivity of $0.5 \mathrm{Au}_{25}-\mathrm{HAP}$ ? To answer this question, we compared the rate constant for the decomposition of $\mathbf{2}$ by the three Au-HAP catalysts in 15 methylcyclohexane. The smallest $0.5 \mathrm{Au}_{25}$ - HAP showed the poorest conversion $(<15 \%)$ while the largest, Au-HAP(IP), showed the highest activity (ESI, † Fig. S9). On the basis of this size effect, we suggest that the high selectivity of $0.5 \mathrm{Au}_{25}-\mathrm{HAP}$ can be explained on the basis of the extremely 20 slow decomposition of 2 by $\mathrm{Au}_{25}$ clusters. The $0.5 \mathrm{Au}_{25}-\mathrm{HAP}$ also showed excellent reusability without any significant loss in either the catalytic activity or the selectivity of the formation of 2 (ESI, $\dagger$ Fig. S10). Finally, we tested the catalytic activity of $0.5 \mathrm{Au}_{25}$-HAP against styrene oxidation in

25 toluene in an $\mathrm{O}_{2}$ atmosphere (1 atm). Microwave heating at $100{ }^{\circ} \mathrm{C}$ for $2 \mathrm{~h}$ yields 2 with a conversin of $22 \%$ and a selectivity of $36 \%$ (ESI, $\uparrow$ Table S3), although the reaction conditions were not optimized.

In summary, we developed a reproducible method $^{16}$ to 30 immobilize $\mathrm{Au}_{25}$ clusters on HAP using $\mathrm{Au}_{25}(\mathrm{SG})_{18}$ as a precursor. The size of the HAP-supported Au clusters after calcination appeared to be $\sim 1.4 \mathrm{~nm}$ by HAADF-STEM observation, slightly larger than that expected for $\mathrm{Au}_{25}(\sim 0.9$ $\mathrm{nm}$ ) with a spherical morphology. The $\mathrm{Au}_{25}$ clusters anchored 35 on HAP exhibited higher catalytic performance than larger clusters in the epoxidation of styrene using TBHP as an oxidant. This catalyst could be reused without significant loss of either activity or selectivity. These observations suggest that small Au clusters on HAP is a promising catalyst for the 40 selective epoxidation of alkenes.

We thank Prof. M. Haruta for valuable comments. This work was financially supported by CREST, JST.

\section{Notes and references}

${ }^{a}$ Catalysis Research Center, Hokkaido University, Nishi 10, Kita 21, 45 Sapporo 001-0021, Japan. E-mail address: tsukuda@cat.hokudai.ac.jp; Fax: +81-11-706-9155; Tel: +81-11-706-9156.

${ }^{b}$ Research Institute for Ubiquitous Energy Devices, National Institute of Advanced Industrial Science and Technology (AIST), 1-8-31 Midorigaoka, Ikeda, Osaka 563-8577, Japan.

$50{ }^{\circ}$ CREST, Japan Science and Technology Agency, Kawaguchi, Saitama 332-0012, Japan.

† Electronic Supplementary Information (ESI) available: optical spectra of $\mathrm{Au}_{25}(\mathrm{SG})_{18}$ in water and on HAP, preparation and characterization 55 TEM images of Au-HAP catalysts, kinetic analysis, result of reuse test. See DOI: 10.1039/b000000x/

¥ Preparation of Catalysts: The $\mathrm{Au}_{25}(\mathrm{SG})_{18}$ precursors were first prepared by following the procedure we reported previously. ${ }^{10}$ The $\mathrm{Au}_{25}(\mathrm{SG})_{18}$ clusters (10.7 mg) and HAP (Sigma Aldrich, $1 \mathrm{~g}$ ) were then dispersed in 60 water and the mixture was stirred for $4 \mathrm{~h}$. The composite of $\mathrm{Au}_{25}(\mathrm{SG})_{18}$ and HAP was collected by filtration and then incubated in vacuo at 300 ${ }^{\circ} \mathrm{C}$ for $2 \mathrm{~h}$.

Catalytic Test: Typically, $50 \mathrm{mg}$ of the Au-HAP catalyst was added to the toluene $(10 \mathrm{~mL})$ solution in a test tube ()$=30 \mathrm{~mm})$ containing $40 \mathrm{mg}$ of 65 styrene and $200 \mathrm{mg}$ of TBHP. The mixture was stirred at a rate of 1200 rpm while the temperature was kept at $80^{\circ} \mathrm{C}$. The products were exracted and identified by gas chromatography (Shimadzu GC-2014) using authentic samples. The yield of product was determined by gas chromatography using the external standard method.

1 T. Hayashi, K. Tanaka and M. Haruta, J. Catal., 1998, 178, 566

2 (a) A. S. K. Hashmi and G. J. Hutchings, Angew. Chem., Int. Ed., 2006, 45, 7896; (b) C. D. Pina, E. Falletta, L. Prati and M. Rossi, Chem. Soc. Rev., 2008, 37, 2077.

753 M. D. Hughes, Y. J. Xu, P. Jenkins, P. McMorn, P. Landon, D. I. Enache, A. F. Carley, G. A. Attard, G. J. Hutchings, F. King, E. H. Stitt, P. Johnston, K. Griffin and C. J. Kiely, Nature, 2005, 437, 1132.

4 M. Turner, V. B. Golovko, O. P. H. Vaughan, P. Abdulkin, A. Berenguer-Marcia, M. S. Tikhov, B. F. G. Johnson and R. M. Lambert, 80 Nature, 2008, 454, 981.

5 (a) P. Lignier, F. Morfin, S. Mangematin, L. Massin, J.-L. Rousset and V. Caps, Chem. Commun., 2007, 2, 186; (b) P. Lignier, S. Mangematin, F. Morfin, J.-L. Rousset and V. Caps, Catal. Today, 2008, 138, 50; (c) D. Gajan, K. Guillois, P. Delichère, J.-M. Basset, J.-P. Candy, V. Caps,

85 C. Copéret, A. Lesage and L. Emsley, J. Am. Chem. Soc. in press, DOI: 10.1021/ja903730q.

6 (a) N. S. Patil, B. S. Uphade, P. Jana, S. K. Bharagava and V. R. Choudhary, J. Catal., 2004, 223, 236; (b) N. S. Patil, B. S. Uphade, P. Jana, S. K. Bharagava and V. R. Choudhary, Catal. Lett., 2004, 94, 89.

907 (a) D. Yin, L. Qin, J. Liu, C, Li and Y. Jin, J. Mol. Catal. A, 2005, 240, 40; (b) L. Luo, N. Yu, R. Tan, Y, Jin, D. Yin and D, Yin, Catal. Let., 2009, 130, 489.

8 (a) J. C. Elliott, Structure and Chemistry of the Apatites and Other Calcium Orthophosphates; Elsevier: Amsterdam, 1994; (b) S.

95 Sugiyama, T. Minami, H. Hayashi, M. Tanaka, N. Shigemoto and J. B. Moffat, J. Chem. Soc., Faraday Trans. 1996, 92, 293.

9 (a) J. Zhu, Z. Knya, V. F. Puntes, I. Kiricsi, C. X. Miao, J. W. Ager, A. P. Alivisatos and G. A. Somorjai, Langmuir 2003, 19, 4396; (b) Y. Tai, J. Murakami, K. Tajiri, F. Ohashi, M. Date and S. Tsubota, Appl. Catal. A 2004, 268, 183; (c) N. Zheng and G. D. Stucky, J. Am. Chem. Soc. 2006, 128, 14278; (d) K. Q. Sun, S. W. Luo, N, Xu and B. Q. Xu, Catal. Lett. 2008, 124, 238.; (e) Y. M. Liu, H. Tsunoyama, T. Akita and T. Tsukuda, J. Phys. Chem. C, 2009, 113, 13457.

10 (a) Y. Negishi, K. Nobusada and T. Tsukuda, J. Am. Chem. Soc., 105 2005, 127, 5261; (b) Y. Shichibu, Y. Negishi, T. Tsukuda and T. Teranishi, J. Am. Chem. Soc., 2005, 127, 13464

11 (a) M. W. Heaven, A. Dass, P. S. White, K. M. Holt and R. W. Murray, J. Am. Chem. Soc., 2008, 130, 3754; (b) J. Akola, M. Walter, R. L. Whetten, H. Häkkinen and H. Grönbeck, J. Am. Chem. Soc., 2008, 110 130, 3756; (c) M. Zhu, C. M. Aikens, F. J. Hollander, G. C. Schatz and R. Jin, J. Am. Chem. Soc. 2008, 130, 5883; (d) M. Zhu, W. T. Eckenhoff, T. Pintauer and R. Jin, J. Phys. Chem. C, 2008, 112, 14221.

12 (a) A. Venugopal and M. S. Scurrel, Appl. Catal. A, 2003, 245, 137; (b) N. Phonthammachai, Z. Ziyi, G. Jun, H. Y. Fan and T. J. White, Gold Bull. 2008, 41, 42; (c) M. I. Domínguez, F. Romero-Sarria, M. A. Centeno and J. A. Odrizola, Appl. Catal. B, 2009, 87, 245; (d) T. Mitsudome, A. Noujima, T. Mizugaki, K. Jitsukawa and K. Kaneda, Chem. Commun. 2009, 5302.

13 W. Yan, S. Brown, Z. Pan, S. M. Mahurin, S. H. Overbury and S. Dai, 120 Angew. Chem., Int. Ed., 2006, 45, 3614.

14 The catalytic activity of HAP is negligibly small; the yield of $\mathbf{2}$ was $<5 \%$ after $16 \mathrm{~h}$ (ESI, $\uparrow$ Fig. S6).

15 The decrease in the selectivity when reaction time is $>12 \mathrm{~h}$ was due to the decomposition of $\mathbf{2}$ into $\mathbf{3}$ and $\mathbf{4}$ (ESI,† Fig. S7).

12516 Lot-to-lot reproducibility of $\mathrm{Au}_{25}$-HAP was confirmed by UV-vis spectroscopy and measurement of the catalytic activity for styrene oxidation. The spectra of the three independently synthesized $\mathrm{Au}_{25}{ }^{-}$ HAP catalysts swere nearly identical. Further, the conversion of $\mathbf{1}$ observed with each of the catalysts was similar with a typical standard 30 deviation of $<5 \%$. 


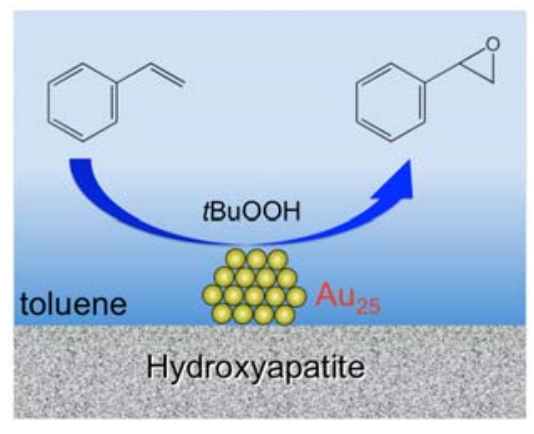

$\mathrm{Au}_{25}$ clusters supported on hydroxyapatite oxidized styrene in toluene with $100 \%$ conversion and $92 \%$ selectivity to the epoxide, under optimum conditions and using anhydrous tert-butyl hydroperoxide (TBHP) as an oxidant. 